\title{
Evaluation of the High Performance Indirect Field Oriented Controlled Dual Induction Motor Drive Fed by a Single Inverter using Type-2 Fuzzy Logic Control
}

\author{
Alaeddine Bounab \\ Department of Electrical Engineering \\ Batna 2 University \\ Batna, Algeria \\ bounab_alaeddine@yahoo.fr
}

\author{
Azeddine Chaiba \\ Department of Industrial Engineering \\ University of Khenchela \\ Khenchela, Algeria \\ chaiba_azeddine@yahoo.fr \\ Department of Electrical Engineering \\ Batna 2 University \\ Batna, Algeria \\ belkacem_sebti@yahoo.fr
}

\begin{abstract}
In this paper, a high-performance indirect field-oriented controlled dual Induction Motor (IM) drive fed by a single inverter using type-2 fuzzy logic control will be presented. At first, the mathematical model of the IM is implemented in the d-q reference frame. Then, the speed control of the Dual Induction Motor (DIM) operating in parallel configuration with Indirect Field Oriented Control (IFOC) using PI and type-2 Fuzzy Logic Controller (T2-FLC) will be presented. For the control of this system, a DC supply and a Space Vector Pulse Width Modulation (SVPWM) voltage source inverter are introduced with constant switching frequency. Also, the performance of T2-FLC, which is based on the IFOC, is tested and compared to those achieved using the PI controller. The simulation results demonstrate that the T2-FLC is more robust, efficient, and has superior dynamic performance for traction system applications.
\end{abstract}

Keywords-Indirect Field Oriented Control (IFOC); Type-2 Fuzzy Logic Control (T2-FLC); Dual Induction Motor (DIM); Space Vector Pulse Width Modulation (SVPWM); mean control strategy

\section{INTRODUCTION}

Nowadays, industrial efforts are focusing on reducing weight and volume and on minimizing costs while guaranteeing high operating performance of the systems. A multi-machine drive system powered by a single inverter presents a desirable solution. These systems are used in several applications such as paper and steel rolling mills [1-3], conveyor systems [4], and electric propulsion systems such as electric traction, ship propulsion and electric vehicles [5-7]. For multi-motor drives, the structure and the control strategy of the drive system depend on the requirements of the application for which they are used as well as the necessary performance, speed and precision of the drive system. Different modeling techniques for two induction motors with a single inverter have already been released. A graphical and a global modeling of a multi-machine system connected in parallel is used in $[6,8]$. Several couplings by criteria merging for multi-machine, multiconverter systems are presented in [9]. Several control solutions have been presented: a modified V/f control strategy for a multi-machine multi-inverter drive system is given in [10] and fuzzy sliding and DTC-SVM control of multi induction motors connected in parallel are presented in $[11,12]$. Authors in [13] present an optimal predictive torque control of two parallel permanent magnet synchronous machines fed with a single inverter. A technique based on master slave direct control of two synchronous machines is used in [14]. Dive systems comprising multi-phase and multi-motor induction machines powered by a single inverter are studied in [15-17]. Unlike the three-phase multi-machine system, multi-phase multi-machine systems supplied by a single inverter can be connected in series $[18,19]$ and in parallel $[13,14,17,20]$, which allows independent control of each machine. In this paper, two induction machines connected in parallel powered by a single inverter as presented in Figure 1 [21] were considered. Here, current and speed feedback is taken from both machines which are fed by a single voltage source inverter for calculating the reference voltages to be applied to the machines.

To obtain a good dynamic response of the drive torque, two performance control strategies can be used to control twomachine systems with a single inverter: Field Oriented Control (FOC) $[5,15,16,21-23]$ and Direct Torque Control (DTC) [1, $4,6,12,24]$. The speed control of the dual identical induction motor drive connected in parallel to a SVPWM inverter supply using T2-FLC is investigated in this paper. This system is 
suitable for applications using dual Induction Motor (IM) drives with the advantage of compactness, lightness and economy [25-27].

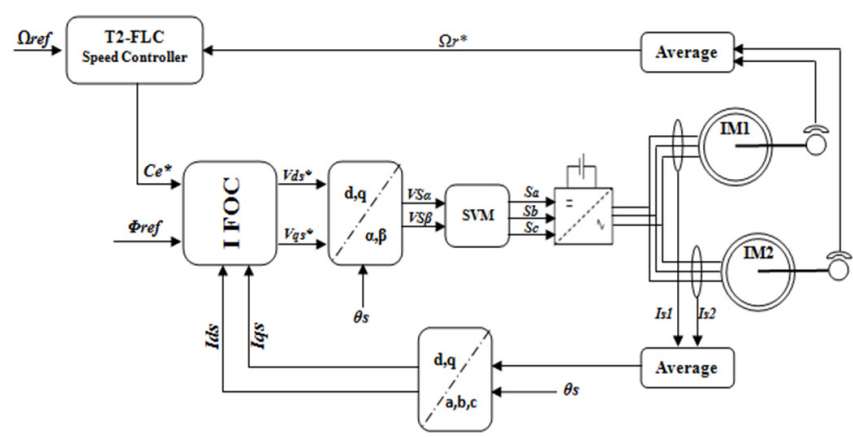

Fig. 1. Block diagram of T2-FLC fuzzy speed control of theDIMs.

\section{SYSTEM CONFIGURATION}

A schematic diagram of the Indirect Field Oriented Control (IFOC) of dual motors connected in parallel associated to a single SVPWM inverter is shown in Figure 1. This method has been adopted in order to avoid the excessive magnetization of these motors [28]. This method is characterized by the calculation of the angular sliding speed, the stator flux angle and the angular speed of the rotor. Speeds of the two induction motors are measured with the help of sensors. T2-FLC or PI controllers are used in the speed control loops for the DIMs. The robustness of the proposed method is checked in terms of motor speed and load variations.

\section{MODEL OF THE INDUCTION MOTOR}

Among the various types of models used to represent the induction machine, there is one that uses each of the stator currents, stator flux, and speed as state variables and voltages $\left(V_{d s}, V_{q s}\right)$ as control variables. This model is presented in $(d, q)$ reference, related to the rotating field. This model is expressed by the system described in (1)-(4):

$$
\left\{\begin{aligned}
V_{d s i} & =R_{s} * I_{d s i}+\frac{d \Phi_{d s i}}{d t}-w_{s i} * \Phi_{q s i} \\
V_{q i} & =R_{s} * I_{q i}+\frac{d \Phi_{q s i}}{d t}+w_{s i} * \Phi_{d s i} \\
V_{d r i} & =0=R_{r} * I_{d r i}+\frac{d \Phi_{d r i}}{d t}-\left(w_{s i}-p \Omega_{i}\right) * \Phi_{q r i} \\
V_{q r i} & =0=R_{r} * I_{q r i}+\frac{d \Phi_{q r i}}{d t}+\left(w_{s i}-p \Omega_{i}\right) * \Phi_{d r i}
\end{aligned}\right.
$$
by:

The components of the stator and rotor flux are expressed

$$
\left\{\begin{array}{l}
\Phi_{d s i}=L_{s} * I_{d s i}+L_{m} * I_{d r i} \\
\Phi_{q s i}=L_{s} * I_{q s i}+L_{m} * I_{q r i} \\
\Phi_{d r i}=L_{r} * I_{d r i}+L_{m} * I_{d s i} \\
\Phi_{q r i}=L_{r} * I_{q r i}+L_{m} * I_{q s i}
\end{array}\right.
$$

The mechanical equation of the machine is given by:

$$
J * \frac{d \Omega i}{d t}+f * \Omega_{i}=C_{e i}-C_{r i}
$$

The electromagnetic torque equation can be expressed in terms of stator currents and stator flux as:

$$
C_{e i}=\frac{3 p L_{m}}{2 L_{r}} p\left(\Phi_{d r i} * I_{q s i}-\Phi_{q r i} * I_{d s i}\right)
$$

where $\left(V_{d s i}, V_{q s i}\right) ;\left(I_{d s i}, I_{q s i}\right) ;\left(\Phi_{d s i}, \Phi_{q s i}\right)$ are the voltage, currents, and stator flux in $d-q$ axis, $\left(w_{s i}, \Omega_{i}\right)$ are stator pulsation and mechanical rotor speed, $i=1,2$ are the first and second induction motor, $\left(R_{s}, R_{r}\right)$ the stator and rotor resistance, $\left(L_{s}, L_{r}\right)$ the stator and rotor cyclic inductance, and $\left(L_{m}, p\right)$ are the mutual inductance and the number of pole pairs.

Due to the similarity of the two induction machines, only the model of one machine is presented.

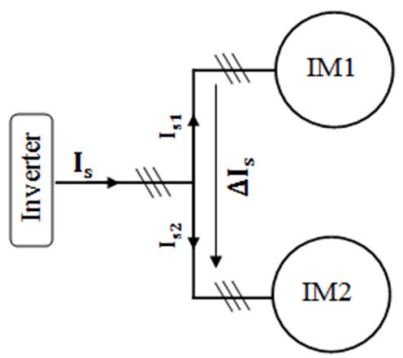

Fig. 2. Current flows for parallel connected dual motor.

In the case of DIMs systems connected in parallel supplied by a single inverter, the current is directly controlled by the inverter, to ensure the proper functioning of the system. The difference between the speeds or the parameters of the two motors causes an imbalance in the currents flowing in each motor. The currents $\left(I_{s 1}\right)$ and $\left(I_{s 2}\right)$, flowing in each stator winding can be represented by $\left(I_{s}\right)$ which flows equally in both stator windings and $\left(\Delta I_{S}\right)$ which circulates between each stator winding as shown in Figure 2. Equations (5) and (6) show the relation of these currents.

$$
\begin{gathered}
I_{s}=I_{s 1}+I_{s 2} \\
\Delta I_{s}=\frac{I_{s 2}-I_{s 1}}{2}
\end{gathered}
$$

\section{CONTROL STRATEGY OF DIMS}

Mean control strategy considers the average of the different input variables of both IMs to create a "virtual mean motor". The measured variables of both motors are the currents $\left(I_{s 1}, I_{s 2}\right)$ and the speeds $\left(\Omega_{1}, \Omega_{2}\right)$. The average variables are obtained using (7) and (8).

$$
\begin{aligned}
& I_{S}=\frac{I_{S 1}+I_{S 2}}{2} \\
& \Omega=\frac{\Omega_{1}+\Omega_{2}}{2}
\end{aligned}
$$

Rotor Field Oriented Control (RFOC) is one of the best methods to drive IMs and presents satisfactory performances. It requires the rotor flux $\left(\Phi_{r}\right)$ and electromagnetic torque $T_{e m}$ to be decoupled. The IM modeling is done in the $(d, q)$ reference frame, with the $d$ axis linked with the rotor flux vector. The rotor flux can be written as:

$$
\Phi_{d r i}=\Phi^{*}{ }_{r i}
$$




$$
\Phi_{\text {qri }}=0
$$

The reference voltages $\left(V_{d s i}, V_{q s i}\right)$ are derived by substituting (9) and (10) in (1)

$$
\left\{\begin{array}{l}
V_{d s i}=R_{s} * I_{d s i}+L_{s} \frac{d I_{d s i}}{d t}-w^{*}{ }_{s i}\left(L_{s} * I_{q s i}+\frac{L_{r}}{R_{r}} * \Phi_{r i}^{*} * w^{*}{ }_{s l i}\right) \\
V_{q s i}=R_{s} * I_{q s i}+L_{s} \frac{d I_{q s i}}{d t}-w^{*}{ }_{s i}\left(L_{s} * I_{d s i}+\Phi_{r i}^{*}\right)
\end{array}\right.
$$

The component references of stator current and slip speed $w^{*}{ }_{s l i}$ can be expressed as:

$$
\begin{gathered}
\left\{\begin{array}{l}
I^{*}{ }_{d s i}=\frac{1}{L_{m}} * \Phi^{*}{ }_{r i} \\
I^{*}{ }_{q s i}=\frac{L_{m}+L_{r}}{p * L_{m} * \Phi^{*} r i} * C^{*}{ }_{e i}
\end{array}\right. \\
w^{*}{ }_{s l i}=\frac{R_{r} * L_{m}}{\left(L_{m}+L_{r}\right) * \Phi^{*}{ }_{r i}} * I^{*}{ }_{q s i}
\end{gathered}
$$

The index $(*)$ represents the command variable. Mean RFOC control offers symmetric behaviors of both motors to obtain stable average performance. On undisturbed functioning, both motors are identical so they have the same behavior. However, when a disturbance affects one motor the second reacts to compensate it, so it is also disturbed. The mean control reacts to offer stable average signals. To generate the reference voltage vectors $\left(V_{d s 1}, V_{q s 1}, V_{d s 2}\right.$ and $\left.V_{q s 2}\right)$, PI controllers are introduced as shown in Figure 1.

\section{PI CONTROLLERS}

The overall system shown in Figure 1 contains two PI controllers. The first is an inner loop for current control, and the second is an outer loop for speed control. The design of the two controllers is detailed in Figures 3 and 4.

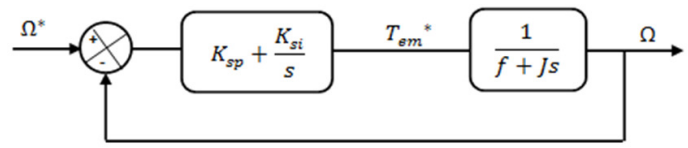

Fig. 3. Speed PI controller block diagram

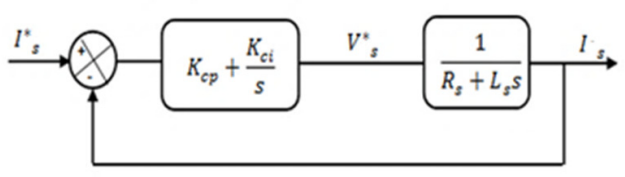

Fig. 4. Current PI controller block diagram.

The PI controller of the speed shown in Figure 3 Is designed as follows:

The transfer function of the PI controller is:

$$
G_{C}(s)=K_{S p}+\frac{K_{S i}}{S}=K_{S p}\left(1+\frac{1}{\left(K_{S p} / K_{S i}\right) \cdot S}\right)=K_{S p}\left(\frac{1+T_{i} \cdot S}{T_{i} \cdot S}\right)
$$

where, $K_{S p}, K_{S i}$ and $T_{i}$ represent, the proportional gain, the integral gains, and the integral time of the controller respectively.

The transfer function of the system is defined as:

$$
G_{S}(s)=\frac{1}{f+J . S}=\frac{1}{f}\left(\frac{1}{1+(J / f) \cdot S}\right)=k\left(\frac{1}{1+\tau_{s} \cdot S}\right)
$$

where, $\tau_{s}$ and $k$ are the time constant and the system gain.

The open loop transfer function of the system $G_{O L}(s)$ is presented as follows:

$$
G_{O L}(s)=G_{C}(s) \cdot G_{S}(s)=K_{S p}\left(\frac{1+T_{i} \cdot S}{T_{i} \cdot S}\right)\left(\frac{k}{1+\tau_{s} \cdot S}\right)
$$

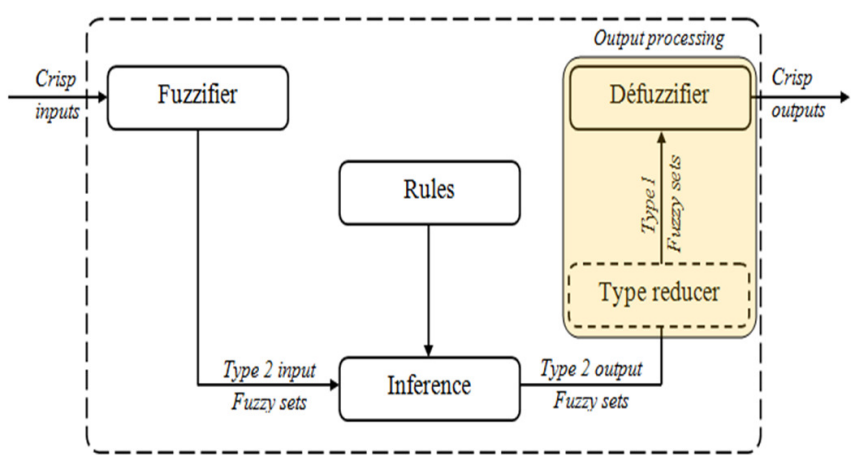

Fig. 5. T2-FLC block diagram.

Let:

$$
\left(1+T_{i} . S\right)=\left(1+\tau_{S} . S\right)
$$

The closed loop transfer function of the system is:

$$
\begin{gathered}
G_{C L}(S)=\frac{G_{O L}(s)}{1+G_{O L}(s)}=\frac{\left(k \cdot K_{S p}\right) /\left(T_{i} \cdot S\right)}{\left(T_{i} \cdot S+k \cdot K_{S p}\right) /\left(T_{i} \cdot S\right)} \\
=\frac{1}{\left(T_{i} / k \cdot K_{S p}\right) \cdot S+1}=\frac{1}{T_{0} \cdot S+1}
\end{gathered}
$$

where $T_{0}$ is the time constant of the closed loop of the system.

According to (14), (15) and (17) the gains of the controller are calculated as:

$$
\begin{gathered}
K_{S i}=\frac{K_{S p}}{T_{i}} \\
K_{S p}=\frac{T_{i}}{k \cdot T_{0}}
\end{gathered}
$$

The value of the time constant of the closed loop of the system $\left(T_{0}\right)$, is the same as the time constant of the system $\left(\tau_{s}\right)$. In the same way the gains $\left(K_{C i}\right)$ and $\left(K_{C p}\right)$ of the PI controller of the current in Figure 4 are obtained from the transfer function of the system which is defined as:

$$
\begin{gathered}
G_{C s}(s)=\frac{1}{R_{S}+L_{S} s}=k c\left(\frac{1}{1+\tau_{C S} s}\right) \\
K_{C i}=\frac{K_{S p}}{T_{i}} \\
K_{C p}=\frac{T_{i}}{k \cdot T_{0}}
\end{gathered}
$$

\section{TYPE 2 FUZZY LOGIC CONTROLLER}

The fuzzy logic control based on Type 2 Fuzzy Sets (T2FS) present a suitable solution for the control of non-linear systems [29]. T2-FS were first proposed in [33-35] as an extension to Type 1 Fuzzy Sets (T1-FS), to increase the 
fuzziness of the relations. Several studies have shown the high performance of T2-FLC, which uses the T2-FS interval instead of Type 1 FLC (T1-FLC) in terms of handling the uncertainties $[17,28,34]$.

In Figure 5, we can see that the T2-FLC differs from the T1-FLC by the output processing block. In addition to the defuzzifier, it includes a block type reducer which allows transforming T2-FS to T1-FS. The Type 2 Fuzzy Controller used in this work has two inputs: the first is the speed error $\left(e_{s}\right)$ and the second is the variation of the speed error $\left(\Delta e_{s}\right)$. The output variable $\left(U_{f}\right)$ generated from the output processing, corresponds to the component of torque $\left(C_{e}\right)$.

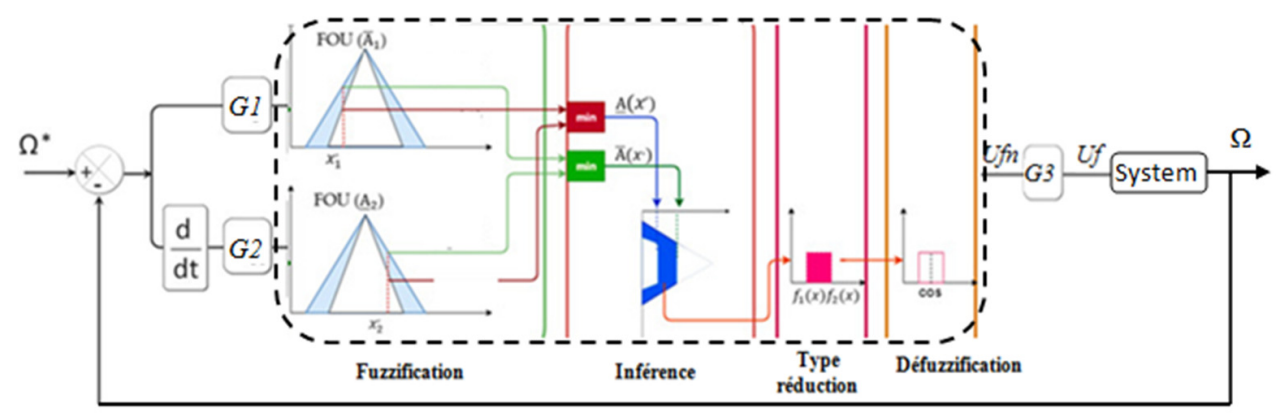

Fig. 6. T2-FLC speed controller.

The membership functions used for the inputs and the output are presented in Figures 7 and 8. The T2-FLC in Figure 6 is characterized by IF-THEN fuzzy rules-base, but its antecedents and consequents are now T2-FS [29, 31, 32].

- Rule 1: if $e_{s}$ is NL, and $\Delta e_{s}$ is NL then $U_{f}$ is NL.

- Rule 2: if $e_{s}$ is NL, and $\Delta e_{s}$ is NM then $U_{f}$ is NL.

- Rule 3: if $e_{s}$ is NL, and $\Delta e_{s}$ is ZR then $U_{f}$ is NL.

- Rule 25: if $e_{s}$ is PL, and $\Delta e_{s}$ is PL then $U_{f}$ is PL.

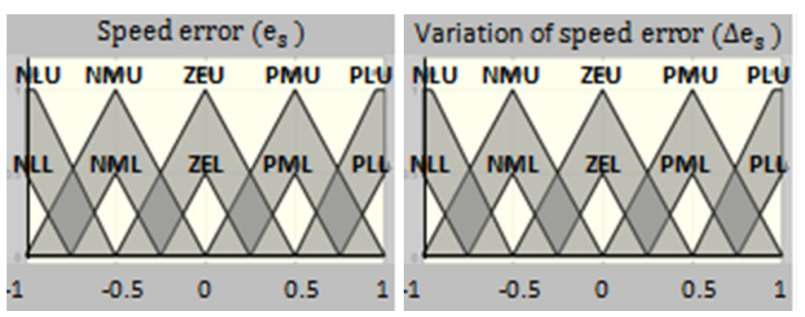

Fig. 7. Inputs membership functions.

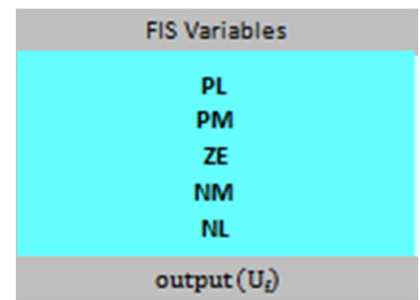

Fig. 8. Output membership function.

The use of a T2-FLC proves to be more advantageous than the use of a PI/PID controller, thanks to its modifiable control surface which offers better performance, especially when the order of the system is greater than two, while it includes oscillatory modes [30].

\section{SPACE VECTOR PULSE WIDTH MODULATION}

The voltage vectors, produced by the 3-phase PWM inverter, divide the space vector plane into six sectors as shown in Figure 9. In every sector, the voltage vector is arbitrary synthesized by the basic space voltage vector of the two sides of one sector and zero vectors. For example, in the first sector, $V_{s}$ ref is a synthesized voltage space vector and its equation is given by [7, 32]:

$$
\begin{gathered}
\vec{V} s_{r e f} * T_{s}=\vec{V}_{0} * T_{0}+\vec{V}_{1} * T_{1}+\vec{V}_{2} * T_{2} \\
T_{s}=T_{0}+T_{1}+T_{2}
\end{gathered}
$$

where $T_{0}, T_{1}$ and $T_{2}$ are the work times of basic space voltage vectors $\vec{V}_{0}, \vec{V}_{1}$, and $\vec{V}_{2}$ respectively. The determination of times $T_{1}$ and $T_{2}$ given by mere projections is given in Figure 10.

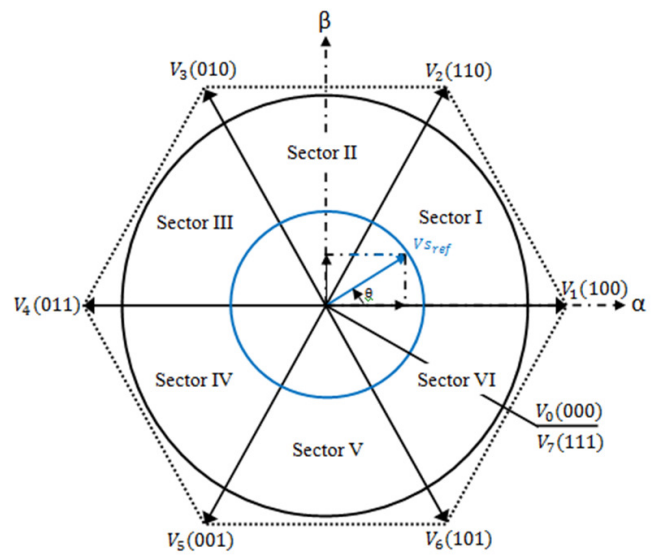

Fig. 9. The diagram of voltage space vectors.

$$
\left\{\begin{aligned}
V s \alpha_{r e f} & =\frac{T_{1}}{T_{s}} *\left|\vec{V}_{1}\right|+x \\
V s \beta_{r e f} & =\frac{T_{2}}{T_{s}} *\left|\vec{V}_{2}\right| * \sin \left(\frac{\pi}{3}\right) \\
x & =\frac{V s \beta_{r e f}}{\tan \left(\frac{\pi}{3}\right)}
\end{aligned}\right.
$$




$$
\left\{\begin{array}{l}
T_{1}=\frac{T_{S}}{2 U_{D C}}\left(\sqrt{6} V s \alpha_{r e f}-\sqrt{2} V s \beta_{r e f}\right) \\
T_{2}=\frac{T_{s}}{U_{D C}}\left(\sqrt{2} V s \beta_{r e f}\right)
\end{array}\right.
$$

The rest of the period is applying the null-vector. The switching duration is calculated for every sector. The times of the vector implementation can all be related to the following variables:

$$
\left\{\begin{array}{l}
X=\frac{T_{s}}{U_{D C}}\left(\sqrt{2} V s \beta_{r e f}\right) \\
Y=\frac{T_{S}}{2 U_{D C}}\left(\sqrt{6} V s \alpha_{r e f}+\sqrt{2} V s \beta_{r e f}\right) \\
Z=\frac{T_{s}}{2 U_{D C}}\left(-\sqrt{6} V s \alpha_{r e f}+\sqrt{2} V s \beta_{r e f}\right)
\end{array}\right.
$$

The implementation of the duration sector boundary vectors can be seen in Table I.

TABLE I. DURATION SECTOR BOUNDARY VECTORS

\begin{tabular}{|c|c|c|c|c|c|c|}
\hline Sector & $\mathbf{1}$ & $\mathbf{2}$ & $\mathbf{3}$ & $\mathbf{4}$ & $\mathbf{5}$ & $\mathbf{6}$ \\
\hline $\boldsymbol{T}_{\boldsymbol{i}}$ & $-\boldsymbol{Z}$ & $\boldsymbol{Y}$ & $\boldsymbol{X}$ & $\boldsymbol{Z}$ & $-\boldsymbol{Y}$ & $-\boldsymbol{X}$ \\
\hline $\boldsymbol{T}_{\boldsymbol{i}+\mathbf{1}}$ & $\boldsymbol{X}$ & $\boldsymbol{Z}$ & $-\boldsymbol{Y}$ & $-\boldsymbol{X}$ & $-\boldsymbol{Z}$ & $\boldsymbol{Y}$ \\
\hline
\end{tabular}

The third step is to compute the duty cycles to have the three necessary times:

$$
\left\{\begin{array}{l}
T a_{\text {on }}=\frac{T_{s}-T_{i}-T_{i+1}}{2} \\
T b_{\text {on }}=T a_{\text {on }}+T_{i} \\
T c_{\text {on }}=T b_{\text {on }}+T_{i+1}
\end{array}\right.
$$

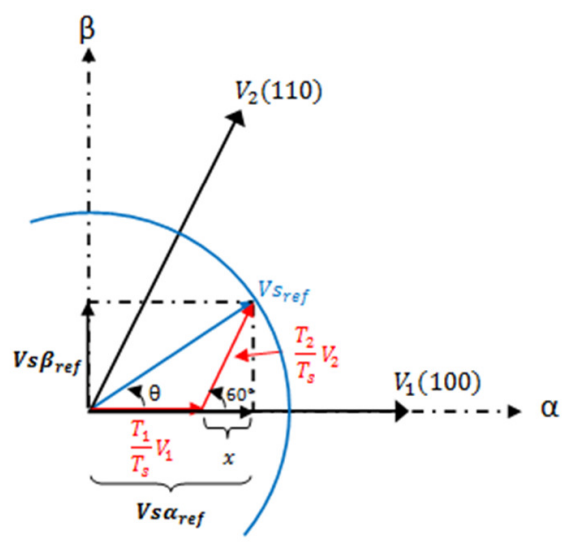

Fig. 10. Projection of the reference voltage vector.

The last step is to assign the duty cycle $\left(T x_{o n}\right)$ to the motor phase according to the sector.

TABLE II. ASSIGNED DUTY CYCLES OF THE PWM OUTPUTS

\begin{tabular}{|c|c|c|c|c|c|c|}
\hline Sector & $\mathbf{1}$ & $\mathbf{2}$ & $\mathbf{3}$ & $\mathbf{4}$ & $\mathbf{5}$ & $\mathbf{6}$ \\
\hline$S_{a}$ & $T a_{o n}$ & $T b_{o n}$ & $T c_{o n}$ & $T c_{o n}$ & $T b_{o n}$ & $T a_{o n}$ \\
\hline$S_{b}$ & $T b_{o n}$ & $T a_{o n}$ & $T a_{o n}$ & $T b_{o n}$ & $T c_{o n}$ & $T c_{o n}$ \\
\hline$S_{c}$ & $T c_{o n}$ & $T c_{o n}$ & $T b_{o n}$ & $T a_{o n}$ & $T a_{o n}$ & $T b_{o n}$ \\
\hline
\end{tabular}

\section{SiMULATION RESULTS AND DISCUSSION}

The modeling and simulation of the system presented in Figure 1 was carried out in MATLAB/Simulink environment. The parameters of the two $4 \mathrm{KW}$ motors used in the simulation are shown in the Appendix. In order to properly test and compare the two speed controllers proposed in terms of performance, firstly both motors are subjected to a trapezoidal speed profile which includes positive and negative values respectively, as shown in Figure 11. Then, each motor undergoes a different load torque, as shown in Figure 12.

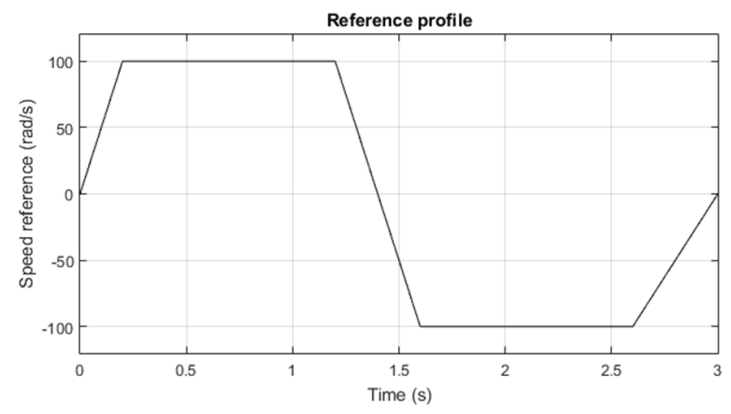

Fig. 11. Speed profile.

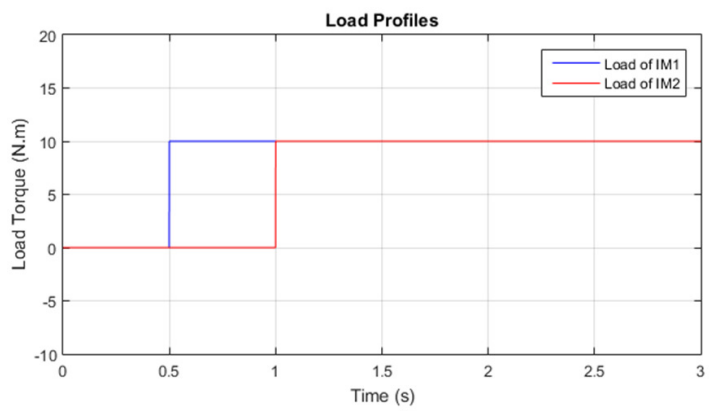

Fig. 12. Load profile.

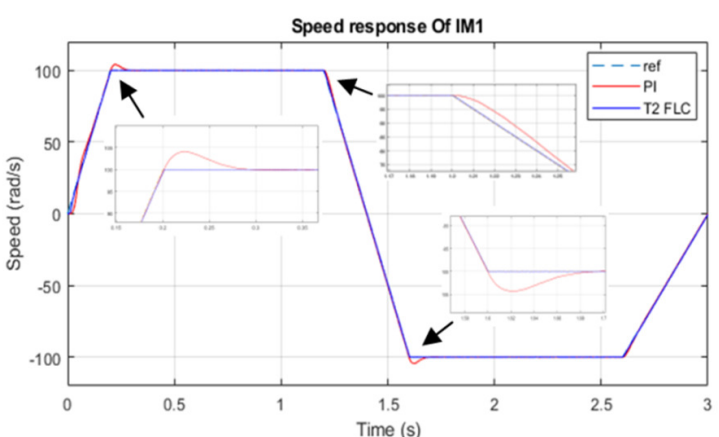

Fig. 13. Speed response of IM1 without perturbation.

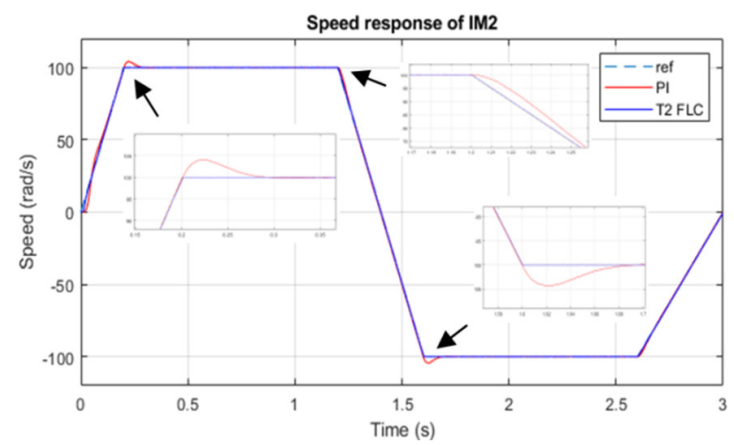

Fig. 14. Speed response of IM2 without perturbation. 


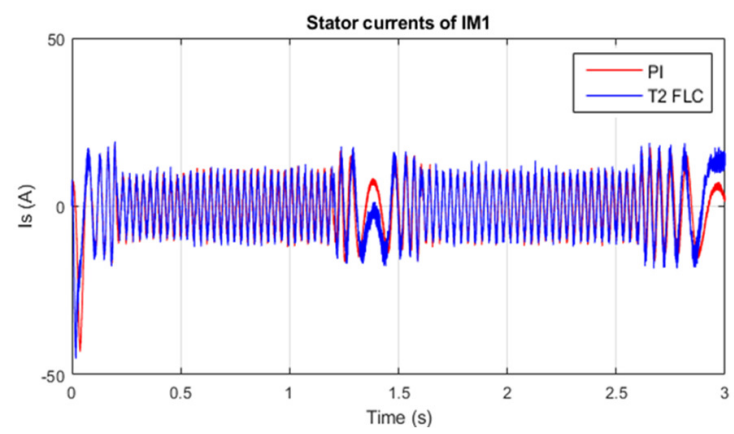

Fig. 15. Stator currents of IM1 with injected load.

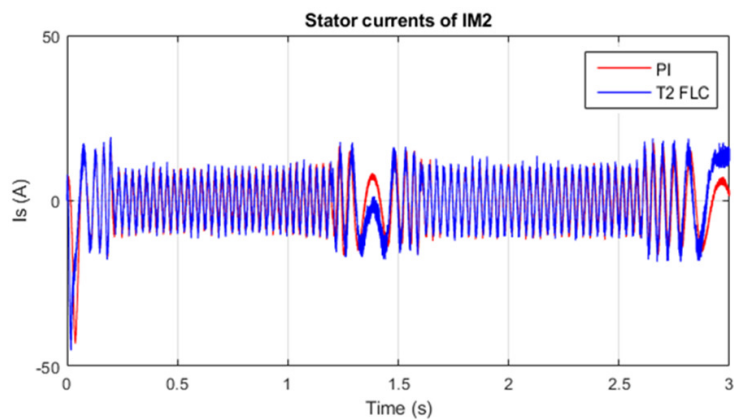

Fig. 16. Stator currents of IM2 with injected load.

The speed response of the two motors with the speed profile introduced is shown in Figures 13 and 14. We can see that the response of both motors is identical, and the amplitude of the transient speed oscillations is lower with T2-FLC which has better rejection of perturbations and responds well to speed reversal as shown in Figures 15 and 16.

TABLE III. COMPARISON OF CALCULATED PERFORMANCE INDICES.

\begin{tabular}{|c|c|c|c|c|c|}
\hline Controller & \multicolumn{2}{|c|}{ MP (rad/s) } & SE & IAE & ITAE \\
\hline PI & 104.17 & -104.36 & 5.489 & 1.347 & 2.094 \\
\hline T2 FLC & 100.02 & -100.01 & 0.994 & 0.887 & 1.196 \\
\hline
\end{tabular}

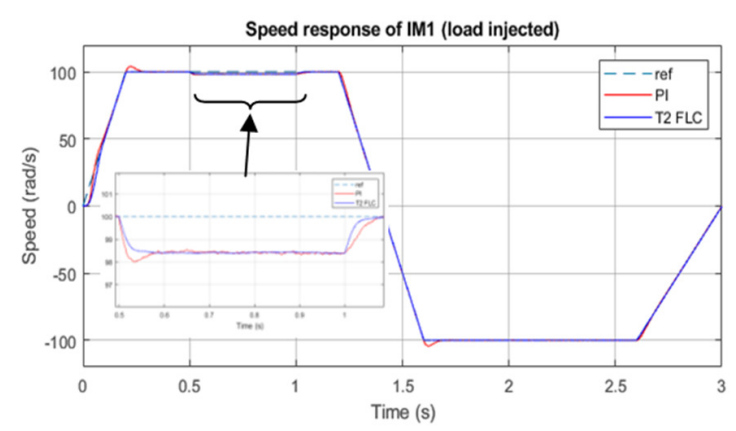

Fig. 17. Speed response of IM1 with injected load.

For a clear comparison between the conventional PI controller and T2-FLC, several performance measures such as Maximum Peak overshoot (MP \%), Integral Squared Error (ISE), Integral Absolute Error (IAE), and Integral of Time Multiplied Absolute Error (ITAE), are computed as shown in Table III. When the operating conditions are not similar for each IM (the introduction of the load torque disturbance profile) the two engines react in a complementary way, i.e. their speeds deviate in an opposite way from the reference, in order to keep the average value of the speed close to the command value. For this, the control by T2-FLC showed better results compared to the PI controller. Finally, the simulation results of the electromagnetic torque of the DIMs connected in parallel associated with IFOC using T2-FLC and PI controllers are presented in Figure 19 for first the IM and Figure 20 for the second IM. These results confirm that the T2-FLC controller offers better performance under changing operating conditions.

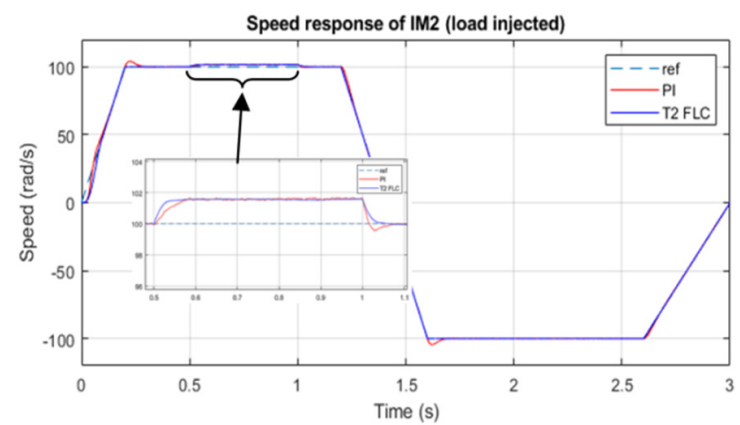

Fig. 18. Speed response of IM2 witht injected load.

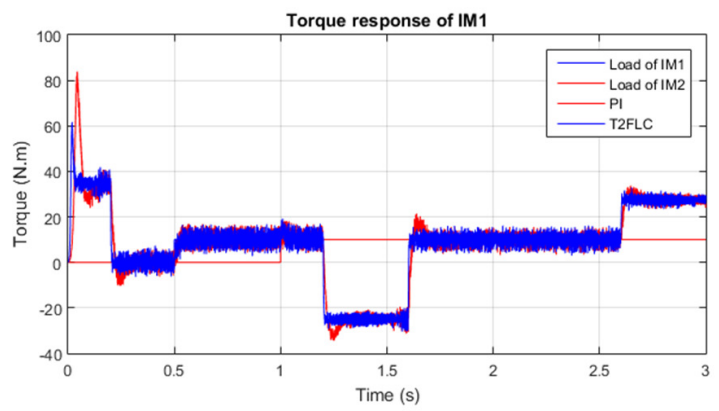

Fig. 19. Torque response of IM1, load profiles injected.

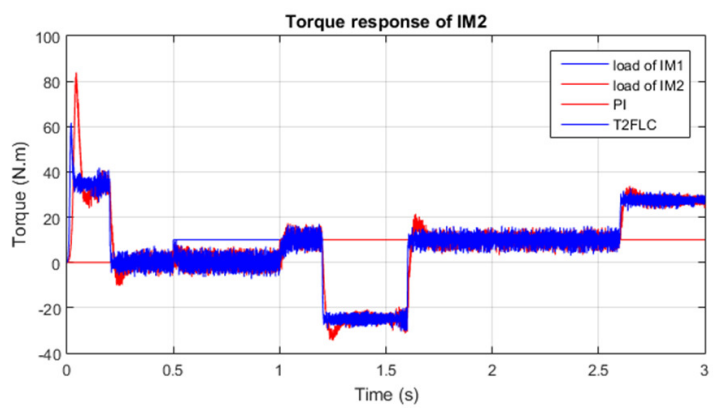

Fig. 20. Torque response of IM1, load profiles injected.

The mean control strategy used in this paper, allowed the identical control of the two-motor drive. The simulation results are supported by the results of [1]. Also the use of T1-FLC proves its high performance for speed control of induction machines compared to the conventional PI/PID controllers, especially in transient mode, which is confirmed by the results obtained by [18], but the T2-FLC developed in this paper gave better results compared to those achieved by [18], which are confirmed by the performance criteria presented in Table III. 


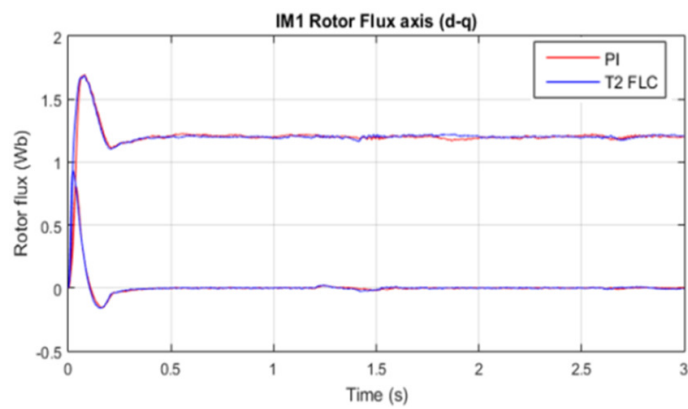

Fig. 21. Rotor flux response of IM1.

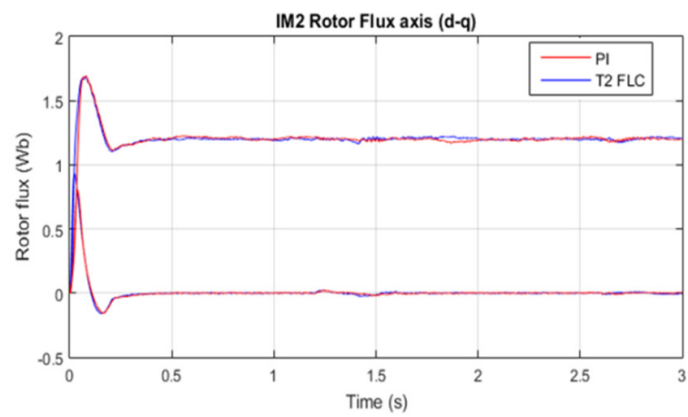

Fig. 22. Rotor flux response of IM2.

\section{CONCLUSION}

In this paper, a high performance indirect field oriented controlled dual induction motor drive fed by a single inverter using type-2 fuzzy logic control has been proposed. This study is based in general on speed control of two induction motors connected in parallel associated to a single SVPWM inverter with constant switching frequency, which uses IFOC as control technique. A comparison of the performances of the two controllers, PI and T2-FLC has been conducted. The proposed IFOC algorithm has been implemented in Matlab/Simulink. The simulation results have shown that the T2-FLC offers better performances compared to the PI controller in terms of DIM speed reference tracking. Also, the transient and steady state response of the motors speed is improved as compared to the conventional PI controller. The presented results show that control based on T2-fuzzy logic offers a desirable solution for applications with several induction motors.

\section{APPENDIX}

INDUCTION MOTORS PARAMETERS

$\quad$ Designation
Rated power
Rated voltage
Nominal frequency
Rated speed
Number of pole pairs
Stator resistance
Rotor resistance
Stator cyclic inductance
Mutual cyclic Inductance
Rotor cyclic inductance
Rotor inertia
Viscosity coefficient

$\begin{array}{cc}\text { Symbol } & \text { Value } \\ \boldsymbol{P}_{\boldsymbol{u}} & 4 \mathrm{KW} \\ \boldsymbol{V}_{\boldsymbol{s}} & 380 \mathrm{~V} \\ \boldsymbol{F} & 50 \mathrm{~Hz} \\ \boldsymbol{N}_{\boldsymbol{n}} & 1440 \mathrm{rpm} \\ \boldsymbol{p} & 2 \\ \boldsymbol{R}_{\boldsymbol{s}} & 1.2 \Omega \\ \boldsymbol{R}_{\boldsymbol{r}} & 1.8 \Omega \\ \boldsymbol{L}_{\boldsymbol{s}} & 0.1554 \mathrm{H} \\ \boldsymbol{L}_{\boldsymbol{m}} & 0.15 \mathrm{H} \\ \boldsymbol{L}_{\boldsymbol{r}} & 0.1568 \mathrm{H} \\ \boldsymbol{J} & 0.07 \mathrm{kgm} \\ \boldsymbol{f} & 0.001 \mathrm{~N} \cdot \mathrm{m} / \mathrm{s}\end{array}$

\section{REFERENCES}

[1] B. M. Joshi and M. C. Chandorkar, "Two-motor single-inverter fieldoriented induction machine drive dynamic performance," Sadhana, vol. 39, no. 2, pp. 391-407, Apr. 2014, doi: 10.1007/s12046-014-0237-6.

[2] I. Ando, M. Sazawa, and K. Ohishi, "High efficient speed control of parallel-connected induction motors with unbalanced load condition using one inverter," in 30th Annual Conference of IEEE Industrial Electronics Society, 2004. IECON 2004, Nov. 2004, vol. 2, pp. 13611366 Vol. 2, doi: 10.1109/IECON.2004.1431776.

[3] T. Inoue, K. Azegami, K. Matsuse, S. Ito, and Y. Nakajima, "Characteristics of sensorless vector controlled multiple induction motor drive connected in parallel fed by a single inverter," in 2011 International Conference on Electrical Machines and Systems, Aug. 2011, pp. 1-6, doi: 10.1109/ICEMS.2011.6073556.

[4] H. Mohktari and A. Alizadeh, "A new multi-machine control system based on Direct Torque Control algorithm," in 2007 7th Internatonal Conference on Power Electronics, Oct. 2007, pp. 1103-1108, doi: 10.1109/ICPE.2007.4692551.

[5] P. M. Kelecy and R. D. Lorenz, "Control methodology for single inverter, parallel connected dual induction motor drives for electric vehicles," in Proceedings of 1994 Power Electronics Specialist Conference - PESC'94, Jun. 1994, vol. 2, pp. 987-991 vol.2, doi: 10.1109/PESC.1994.373800.

[6] R. Pen-Eguiluz, M. Pietrzak-David, V. Riga, and B. de Fornel, "Comparison of several speed sensorless strategies of two different dual drive induction motor control structures," in VIII IEEE International Power Electronics Congress, 2002. Technical Proceedings. CIEP 2002. Oct. 2002, pp. 41-46, doi: 10.1109/CIEP.2002.1216634.

[7] W. Ruxi, W. Yue, D. Qiang, H. Yanhui, and W. Zhaoan, "Study of control methodology for single inverter parallel connected dual induction motors based on the dynamic model," in 2006 37th IEEE Power Electronics Specialists Conference, Jun. 2006, pp. 1-7, doi: 10.1109/pesc.2006.1711845.

[8] A. Bouscayrol et al., "Multi-machine multi-converter system for drives: analysis of coupling by a global modeling," in Conference Record of the 2000 IEEE Industry Applications Conference. Thirty-Fifth IAS Annual Meeting and World Conference on Industrial Applications of Electrical Energy (Cat. No.00CH37129), Oct. 2000, vol. 3, pp. 1474-1481 vol.3, doi: 10.1109/IAS.2000.882078

[9] A. Bouscayrol et al., "Control structures for multi-machine multiconverter systems with several couplings by criteria merging," in 2005 European Conference on Power Electronics and Applications, Sep. 2005, doi: 10.1109/EPE.2005.219575.

[10] J. Iyer, K. Tabarraee, S. Chiniforoosh, and J. Jatskevich, "An improved $\mathrm{V} / \mathrm{F}$ control scheme for symmetric load sharing of multi-machine induction motor drives," in 2011 24th Canadian Conference on Electrical and Computer Engineering(CCECE), May 2011, pp. 001487001490, doi: 10.1109/CCECE.2011.6030711.

[11] C. Sun, G. Gong, H. Yang, and F. Wang, "Fuzzy sliding mode control for synchronization of multiple induction motors drive," Transactions of the Institute of Measurement and Control, vol. 41, no. 11, pp. 32233234, Jul. 2019, doi: 10.1177/0142331218817100.

[12] M. Jafari, K. Abbaszadeh, and M. Mohamadian, “A novel DTC-SVM approach for two parallel-connected induction motors fed by matrix converter," Turkish Journal of Electrical Engineering \& Computer Sciences, vol. 26, no. 3, pp. 1599-1611, May 2018, doi: doi:10.3906/elk1611-168.

[13] A. Bouarfa and M. Fadel, "Optimal Predictive Torque Control of Two PMSM supplied in Parallel on a Single Inverter," IFAC-PapersOnLine, vol. 48, no. 30, pp. 84-89, Jan. 2015, doi: 10.1016/j.ifacol.2015.12.358.

[14] K. Hartani, F. Maata, and A. Merah, "Sensorless Master-slave Direct Torque Control of Permanent Magnet Synchronous Motors Based on Speed MRAS Observer in Electric Vehicle," Research Journal of Applied Sciences, Engineering and Technology, vol. 7, no. 23, pp. 50345048-5048, 2014, doi: 10.19026/rjaset.7.897.

[15] E. Levi, R. Bojoi, F. Profumo, H. A. Toliyat, and S. Williamson, "Multiphase induction motor drives - a technology status review," IET 
Electric Power Applications, vol. 1, no. 4, pp. 489-516, Jul. 2007, doi: 10.1049/iet-epa:20060342.

[16] E. Levi, M. Jones, S. N. Vukosavic, and H. A. Toliyat, “A novel concept of a multiphase, multimotor vector controlled drive system supplied from a single voltage source inverter," IEEE Transactions on Power Electronics, vol. 19, no. 2, pp. 320-335, Mar. 2004, doi: 10.1109/TPEL.2003.823241.

[17] Z. Tir, O. P. Malik, and A. M. Eltamaly, "Fuzzy logic based speed control of indirect field oriented controlled Double Star Induction Motors connected in parallel to a single six-phase inverter supply," Electric Power Systems Research, vol. 134, pp. 126-133, May 2016, doi: 10.1016/j.epsr.2016.01.013.

[18] T. Bessaad, R. Taleb, and A. Belboula, "Fuzzy adaptive control of a series connected tow-motor six-phase driver system with seven-level single inverter supply," Przeglad Elektrotechniczny, vol. 95, no. 7, pp. 51-59, 2019, doi: 10.15199/48.2019.07.12.

[19] J. M. Lazi, Z. Ibrahim, M. Sulaiman, A. M. Razali, and N. Kamisman, "Independent control for dual-PMSM drives using Five-Leg Inverter," in 2015 IEEE Conference on Energy Conversion (CENCON), Oct. 2015, pp. 143-148, doi: 10.1109/CENCON.2015.7409529.

[20] N. L. Nguyen, M. Fadel, and A. Llor, "Predictive Torque Control - A solution for mono inverter-dual parallel PMSM system," in 2011 IEEE International Symposium on Industrial Electronics, Jun. 2011, pp. 697 702, doi: 10.1109/ISIE.2011.5984242.

[21] B. M. Joshi, D. C. Patel, and M. C. Chandorkar, "Machine interactions in field oriented controlled multi-machine three phase induction motor drives," in 2011 IEEE International Electric Machines Drives Conference (IEMDC), May 2011, pp. 342-347, doi: 10.1109/ IEMDC.2011.5994617.

[22] Y. Kouno, H. Kawai, S. Yokomizo, and K. Matsuse, "A speed sensorless vector control method of parallel connected dual induction motor fed by a single inverter," in Conference Record of the 2001 IEEE Industry Applications Conference. 36th IAS Annual Meeting (Cat. No.01CH37248), Sep. 2001, vol. 2, pp. 1218-1223 vol.2, doi: 10.1109/ IAS.2001.955652.

[23] B. M. Joshi and M. C. Chandorkar, "Power failure ride-through in multimachine drives," in 2012 IEEE Energy Conversion Congress and Exposition (ECCE), Raleigh, NC, USA, Sep. 2012, pp. 3633-3640, doi: 10.1109/ECCE.2012.6342309.

[24] P. Escane, M. Pietrzak-David, and B. de Fornel, "Optimisation of a railway traction system drive control vs. slip perturbation," in Conference Record of the 2000 IEEE Industry Applications Conference. Thirty-Fifth IAS Annual Meeting and World Conference on Industrial Applications of Electrical Energy (Cat. No.00CH37129), Rome, Italy, Oct. 2000, vol. 3, pp. 1909-1916, doi: 10.1109/IAS.2000.882139.

[25] A. Bouscayrol, M. Pietrzak-David, P. Delarue, R. Pena-Eguiluz, P.-E. Vidal, and X. Kestelyn, "Weighted Control of Traction Drives With Parallel-Connected AC Machines," IEEE Transactions on Industrial Electronics, vol. 53, no. 6, pp. 1799-1806, Dec. 2006, doi: 10.1109/ TIE.2006.885106.

[26] Y. Lee and J.-I. Ha, "Control Method for Mono Inverter Dual Parallel Surface-Mounted Permanent-Magnet Synchronous Machine Drive System," IEEE Transactions on Industrial Electronics, vol. 62, no. 10, pp. 6096-6107, Oct. 2015, doi: 10.1109/TIE.2015.2420634.

[27] K. Matsuse, H. Kawai, Y. Kouno, and J. Oikawa, "Characteristics of speed sensorless vector controlled dual induction motor drive connected in parallel fed by a single inverter," IEEE Transactions on Industry Applications, vol. 40, no. 1, pp. 153-161, Jan. 2004, doi: 10.1109/ TIA.2003.821805.

[28] F. Amrane and A. Chaiba, "Performences of Type-2 Fuzzy Logic Control and Neuro-Fuzzy Control Based on DPC for Grid Connected DFIG with Fixed Switching Frequency," International Journal of Electrical and Computer Engineering, vol. 10, no. 7, pp. 870-878, Apr. 2016.

[29] K. T. P. Tee, R. Hosseinnezhad, M. Brandt, and J. Mo, "Study on Application of Interval Type 2 Fuzzy Logic Control for Gap Width Controller Used in EDM Machine," Applied Mechanics and Materials, vol. 365-366, pp. 863-869, 2013, doi: 10.4028/www.scientific.net/ AMM.365-366.863.
[30] E. H. Mamdani, “Application of fuzzy algorithms for control of simple dynamic plant," Proceedings of the Institution of Electrical Engineers, vol. 121 , no. 12 , pp. 1585-1588, Dec. 1974, doi: 10.1049/piee. 1974.0328.

[31] L. Keltoum and B. Leila, "Type-2 Fuzzy Logic Control of a Doubly-Fed Induction Machine (DFIM)," International Journal of Artificial Intelligence, vol. 4, no. 4, pp. 139-152, Dec. 2015, doi: 10.11591/ ijai.v4.i4.pp139-152.

[32] K. Zhou and D. Wang, "Relationship between space-vector modulation and three-phase carrier-based PWM: a comprehensive analysis [threephase inverters]," IEEE Transactions on Industrial Electronics, vol. 49, no. 1, pp. 186-196, Feb. 2002, doi: 10.1109/41.982262.

[33] F. Z. Kebbab, D. E. C. Belkhiat, D. Jabri, and S. Belkhiat, "Frequency Speed Control of Rotary Travelling Wave Ultrasonic Motor Using Fuzzy Controller," Engineering, Technology \& Applied Science Research, vol. 8, no. 4, pp. 3276-3281, Aug. 2018.

[34] H. Rahali, S. Zeghlache, and L. Benalia, "Adaptive field-oriented control using supervisory type-2 fuzzy control for dual star induction machine," International Journal of Intelligent Engineering and Systems, vol. 10, no. 4, pp. 28-40, 2017, doi: 10.22266/ijies2017.0831.04.

[35] E. Nechadi, "Adaptive Fuzzy Type-2 Synergetic Control Based on Bat Optimization for Multi-Machine Power System Stabilizers," Engineering, Technology \& Applied Science Research, vol. 9, no. 5, pp. 4673-4678, Oct. 2019. 